\title{
Development of prediction tools for diarrhea and rash in breast cancer patients receiving lapatinib in combination with capecitabine: rule of thumb in prediction studies
}

\author{
Siamak Sabour
}

Received: 11 October 2014/ Accepted: 16 October 2014/Published online: 25 October 2014

(C) Springer Science+Business Media New York 2014

To the Editor,

I was interested to read the paper by Dranitsaris $G$ and colleagues published in Breast Cancer Res Treat 2014 Oct. The purpose of the authors was to predict the risk of $\geq$ grade 2 diarrhea and rash prior to each cycle of Lapatinib and Capecitabine (L-CAP) in HER-2-positive patients with metastatic breast cancer (MBC) [1].

They used generalized estimating equations to develop the risk models using a backward elimination process. A receiver operating characteristic curve (ROC) analysis was undertaken to measure the predictive accuracy of the scoring algorithms [1].

For prediction studies, we need two different cohort datasets or at least one cohort dataset splitting that to develop our prediction model and then to validate it. Without validation of prediction models, most of the times, misleading results may be the main outcome of such researches [2-5].

They concluded that their models provide patient-specific risk information that could be helpful in assessing the risks and benefits of L-CAP in the MBC patients. Such a conclusion may have limited generalizability due to no validation of prediction model which is a rule of thumb in prediction studies.

\section{References}

1. Dranitsaris G, Lacouture ME (2014) Development of prediction tools for diarrhea and rash in breast cancer patients receiving lapatinib in combination with capecitabine. Breast Cancer Res Treat 147(3):631-638

2. Jeckel JF, Katz DL, Elmore JG, Wild DMG (2007) The study of causation in epidemiologic investigation and research. In: Jeckel JF (ed) Epidemiology, biostatistics and preventive medicine, 3rd edn. Elsevier, Philadelphia, pp 64-66

3. Rothman KJ, Greenland S, Lash TL (2008) Cohort studies. In: Rothman KJ (ed) Modern epidemiology, 3rd edn. Lippincott Williams \& Wilkins, Baltimore, pp 79-85

4. Sabour S (2014) Obesity predictors in people with chronic spinal cord injury: a common mistake. J Res Med Sci 19(1):80

5. Sabour S, Ghassemi F (2013) Predictive value of confocal scanning laser for the onset of visual field loss. Ophthalmology 120(6):e31-e32. doi:10.1016/j.ophtha.2013.01.055 